\title{
Doseles de aliso y crecimiento de planitas acuáticas
}

\author{
F. Bermúdez de Castro ${ }^{1}$; P. Barbero ' ;. G. Martín ${ }^{2}$
}

1 Cátedra de Ecología, Facultad de Biología. Universidad Complutense. Madrid 3

2 I. B. Simancàs. Madrid 17

SUMMARY

\section{ALDER CANOPIES AND GROWTH OF AQQUATIC PLANTS}

The effect of alder canopies upon aquatic plants is. studied in River Guadalix and in Retuerta Brokk (near Madrid, Spain). In places with polluted water as well as in those without pollution; alder canopy avoids the growth of algae and aquatic plants suchs as Lemna sp. and Ranuncultus sp.

\section{INTRODUCCION}

Alnus glutinosa (L.) Gaertn., aliso, es un árbol de porte piramidal, de $20 \mathrm{~m}$. de altura, muy común en la Península Ibérica. Por ser estenohidro en las zonas de influencia oceánica aparece rodeando cursos de agua y prados y formando bosquetes, mientras que en las zonas de clima mediterráneo-continental se. alinea a lo largo de las orillas de los ríos $y$ arroyos donde forma ripisilvas que se propagan por retoños y semillas, por lo que no es raro ver agrupaciones de árboles brotados de cepa o nacidos de semilla en diferentes estadios de crecimiento (BERMUDEZ DE CASTRO, 1977; MERINO \& BERMUDEZ DE CASTRO, 1982; SCHMITZ \& BERMUDEZ DE CASTRO, 1982). En simbiosis radical con Frankia alni fija nitró- geno atmosférico con valsres medios de actividad nitrogenásica para la zona Centro de España entre 500 y 900 nanomoles de etileno por gramo de nódulo fresco y hora, con máximos de 5023.5 (SCHMITZ \& BERMUDEZ DE CASTRO; 1982).

El nitrógeno es uno de los principales factores limitantes en ecosistemas terrestres y dulceacuícolas; concentraciones muy bajas en las aguas limitan la producción de los lagos (FOGG, 1971) y de los cursos de agua (GRANDHALL \& LUNDGREN, 1971). Sin embargo, donde crecen alisos aumenta la producción primaria de las aguas como se ha visto en lagos del Reino Unido y como observó GOLDMAN (1961) en el lago Castle (California), cuyas aguas cercanas a una aliseda de $A$. tenuifolia contenían $17 \%$ más de nitrógeno que las aguas alejadas de 
estos árboles. Estos incrementos de nitrógeno son debidos al retorno al suelo y al agua de compuestos nitrogenados a través de excreciones radicales, del agua de lluvia que lava troncos y ramas (SILVESTER, 1977), de la descomposición del lecho de hojarasca y de la necrosis nodular. Por ello aumenta la producción de los suelos (BERMUDEZ DE CASTRO, 1981) y puede aumentar en las aguas.

Sin embargo, no se alcanzan valores excesivos ni se acelera la eutrofización, ya que el dosel de aliso impide el crecimiento de plantas de ciclo largo dentro del agua. En efecto, las hojas de color verde oscuro, al absorber selectivamente en el espectro visible y reflejar parte de la luz solar incidente, provocan situaciones de penumbra bajo el dosel que se prolongan hasta fines de otoño, pues el aliso mantiene las hojas más tiempo que otros árboles ripícolas. Además estos árboles tienen un sistema radical muy desarrollado por lo que retardan la erosión fluvial, estabilizan las orillas y disminuyen el aterramiento de los cauces (SCHMITZ \& BERMUDEZ DE CASTRO, 1982). Este hecho unido a su crecimiento rápido hace que estén indicados para regular las redes hidrográficas, como se hace en varias naciones de América Central (BUDOWSKI, 1979) y en Colombia por indicación de la F.A.O.

En este trabajo se estudia el efecto de alisedas espontáneas sobre el crecimiento de algas y vegetación sumergida en un tramo contaminado por materia orgánica del río Guadalix (Madrid) y en otro sin contaminar del arroyo Retuerta (Avila).

\section{MATERIAL Y METODOS}

\section{ANALISIS DE AGUAS}

Se recogieron muestras simples de agua que, $\sin$ fijar, se trasladaron al laboratorio en botellas cerradas dentro de una nevera a $45^{\circ} \mathrm{C}$. Con ellas se realizaron los análisis de D.Q.O. y D.B.O. 5 según las normas de los STANDARD METHODS FOR THE EXAMINATION OF WATER AND WASTEWATER
(1980). La conductividad y el pH se midieron in situ.

\section{OBSERVACIONES SOBRE EL CRECIMIENTO DE LA VEGETACION}

Se hicieron diversas observaciones de $v i$ su y se recogió el material para su tipificación durante los meses de octubre y noviembre de 1981 en una época en la que, por efecto de la sequía prolongada, el caudal de los ríos era notablemente inferior al habitual.

\section{RESULTADOS}

\section{RIO GUADALIX}

La zona observada (fig. 1) comprende un tramo de rio aguas abajo del pantano de $\mathrm{El}$ Vellón, desde el puente de la carretera de El Molar a San Agustín de Guadalix hasta el puente de la carretera que atraviesa este último pueblo. El río discurre bajo el dosel de alisos, interrumpido en algunos puntos en los que se encuentran prados de extensión reducida, hasta llegar a una fábrica de papel que vierte las aguas residuales a cielo abierto y sin depuración. A partir de aqui, desaparece la aliseda y sólo se advierten grupos de 3 ó 4 árboles muy separados entre sí.

Hasta cerca de la fábrica el agua aparece clara, se ve el fondo y contiene numerosos peces, siendo un lugar preferido por los pescadores de la zona. El $\mathrm{pH}$, conductividad, D.Q.O. y D.B.O.5 aparecen en la tabla I. Desde este punto y debido al efluente de la fábrica de papel, el agua aparece contamina$\mathrm{da}$, de color negro y con malos olores. La conductividad aumenta en 490 unidades, la D.Q.O. en 513 y la D.B.O. 5 en 583. Sobre los cantos rodados del lecho del río que, durante el estiaje, quedan al descubierto se depositan capas de pasta de cartón arrastrada por el agua, las cuales, al secarse, forman una costra de varios centímetros de espesor. 

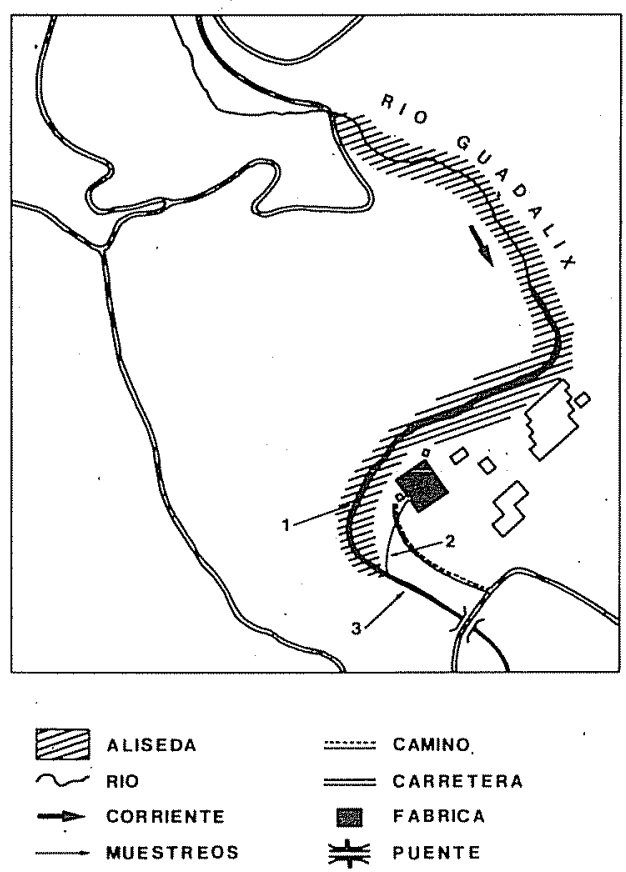

Fig. 1. Zona de muestreo en el río Guadalix.

\section{ARROYO RETUERTA}

La zona de estudio está situada en el término de Las Navas del Marqués y comprende un pequeño embalse en la urbanización de La Ciudad Ducal y un tramo del arroyo.

TABLA I. Características de las aguas del río Guadalix en la zona de muestreo.

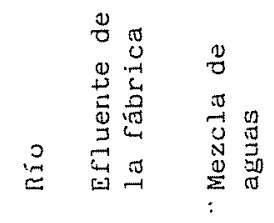

$\mathrm{pH}$

Conductividad

(us/cm)

D.Q.O. ( $\mathrm{mg} / \mathrm{I})$

D.B. $0.5(\mathrm{mg} / \mathrm{I})$

$\begin{array}{rrr}6,0 & 5,8 & 6,0 \\ 357 & 721 & 847 \\ 201 & 873 & 714 \\ 92 & 670 & 630\end{array}$

$\mathrm{pH}$

Conductividad

( $\mathrm{us} / \mathrm{cm}$ )

D.Q.O. (mg/1)

D.B.0.5 (mg/1)
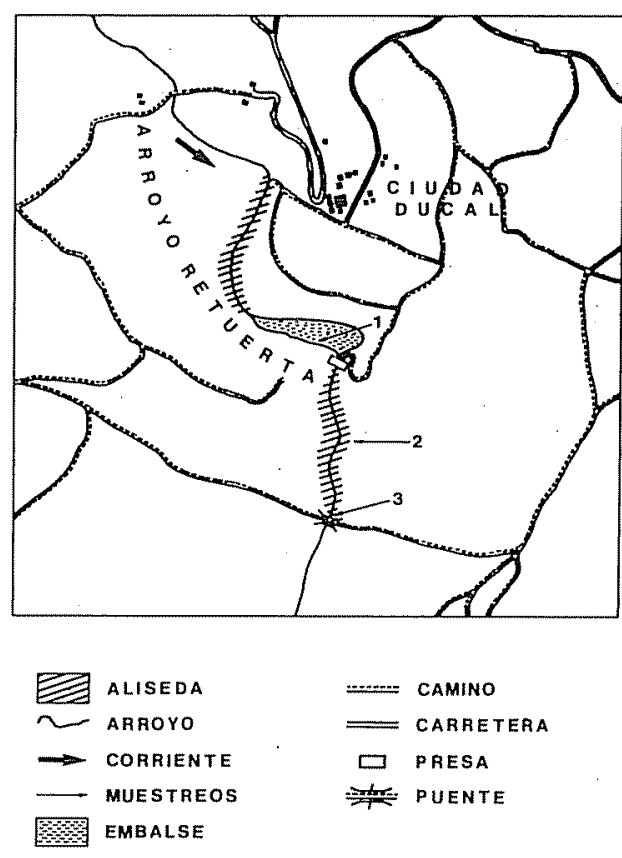

Fig. 2. Localización de la zona muestreada en el arroyo Retuerta.

aguas abajo del embalse (fig. 2). El arroyo, muy estrecho, circula bajo un dosel denso de alisos interrumpido solamente en las inmediaciones de un camino de tierra que atraviesa el arroyo por un puente.

No hay prácticamente vertidos durante la

TABLA II. Características de las aguas del arroyo Retuerta en la zona de muestreo.

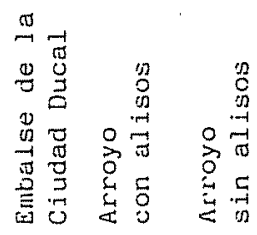

$$
\begin{array}{rrr}
5,8 & 5,8 & 6,0 \\
621 & 141 & 138 \\
17 & 29 & 22 \\
6 & 4 & 8
\end{array}
$$


época de las observaciones ya que en otoñoinvierno la urbanización está prácticamente deshabitada. En las orillas del embalse ha desaparecido el soto ribereño de alisos y sólo quedan contados ejemplares de porte arbustivo por retoño de tocones. Las aguas son de gran pureza como se advierte por los datos de la tabla II.

\section{EFECTO DEL DOSEL DE ALISOS}

Tanto en el río Guadalix como en el arroyo Retuerta se observa la influencia del dosel de alisos que impide el crecimiento de algas $\mathrm{y}$ angiospermas acuáticas.

En los tramos del río Guadalix en que los alisos forman ripisilvas en ambas orillas y el agua discurre bajo el dosel no aparecen algas macroscópicas ni plantas superiores enraizadas. En los tramos con prados ribereños las aguas están cubiertas de masas de cloroficeas (Cladophoraceae) cerca de las orillas sin árboles, o bien de Ranunculus sp. La vegetación de los cauces desaparece cuando la aliseda, recuperada, vuelve a dar sombra al río.

Más abajo se ensancha el cauce y los alisos forman grupos pequeños distanciados unos de otros. Aqui hay zonas extensas cubiertas de algas. Sin embargo, debajo de los árboles aparecen corros casi semicirculares en los que no se advierte crecimiento de algas macroscópicas, estableciendo las fronteras entre las zonas con vegetación y sin ella el paso del agua sombreada al agua expuesta al sol. Aguas abajo del efluente de la fábrica, por el efecto de los vertidos, no existen plantas acuáticas.

En el arroyo Retuerta la situación es parecida. Amplias zonas del embalse, cerca de las orillas, se encuentran cubiertas por masas de clorofíceas. Bajo los alisos no crece vegetación macroscópica en el arroyo, mientras que en el tramo sin árboles, cerca del puente, desde el borde del último aliso de la alineación, el agua aparece cubierta por un manto de Lemna sp.

\section{DISCUSION}

La distribucicin de las plantas acuáticas está relacionada con la calidad y cantidad de radiación visible que filtra el dosel de árboles y arbustos riparios. Mientras especies como Sparganium emersum pueden vivir continuamente sombreadas, otras como Verónica beccabunga necesitan mucha luz, de tal manera que se establece una división de las especies acuáticas según su tolerancia frente a la luz (HASLAM, 1978).

Aunque cualquier árbol de ribera da sombra al rio y controla el crecimiento de la vegetación de los cauces, por lo que se puede establecer una relación entre esta última y la flora de los sotos ribereños (FASSETT, 1957), los alisos por la intensidad y la duración del dosel ejercen un control más efectivo, por lo que HASLAM (1978) recomienda emplearlos para regular los cursos de agua en las Islas Británicas y eñ el Continente Europeo.

Los resultados de las observaciones de la flora acuática en los sitios muestreados apuntan hacia un control efectivo de la vegetación de los ríos por los̆ alisos, ya que bajo estos árboles no se encontraban cantidades apreciables de algas, no crecían las especies de luz como Ranunculus, ni plantas flotantes como Lemna sp. que toleran ciertas situaciones de sombra. Por otra parte, la frontera entre la zona de agua cubierta de vegetación y las aguas sin plantas macroscópicas coincidian con los límites de la zona sombreada por $A$. glutinosa.

Los efectos aparentemente contrarios de los alisos sobre comunidades acuáticas: añadir compuestos nitrogenados, que estimulan el crecimiento, y ensombrecer el rio durante un período largo de tiempo, que inhibe el crecimiento, constituyen un control eficaz que mantiene un nivel de producción deseable en las aguas e impide las situaciones de eutrofización. Si a esto añadimos la consolidación de las orillas parece conveniente seguir las recomendaciones de Haslam (1978) y repoblar las orillas de los rios de la 
zona Centro de la Península Ibérica $\operatorname{con} A$. glutinosa, sin desdeñar otras especies actinorrizas que, ef determinadas situaciones, pueden contribuir a regular los cauces (BERMUDEZ DE CASTRO, 1980).

\section{AGRADECIMIENTOS}

A E. Molera por la ayuda prestada para la recogida de muestras y análisis de las mismas y a V. Zamorano por la realización de las gráficas.

\section{BIBLIOGRAFIA}

BERMUDEZ DE CASTRO, F, 1977. Angiospermas no leguminosas fijadoras de nitrógeno de la $\mathrm{Pe}$. nínsula Ibérica. Bol. Est. Cent. Ecol., 6: 3-17.

- 1980. Incidencia de las plantas actinorrizas en la regulación de los cauces. Conferencia Europea sobre Saneamiento de las Ciudades. Madrid.

- 1981. Diazotrofía como técnica en Agronomía y Silvicultura. En: Productividad Vegetal. C. Vicente (ed.). Ed. Univ. Complutense, Madrid. págs. 193-225.

Univ.'Complutense. Madrid. págs. 193-225.

BUDOWSKI, G. 1979. Int. Conf on Coop. in Agroforestry. Nairobi. Kenya. 31 pp.

FASSETT, N.C. 1957. A Manual of Aquatic Plants. Univ. Wisconsin Press. Madison.

FOGG, G.E. 1971. Nitrogen Fixation in Lakes. Plant and Soil. Special vol., 393-401.

GOLDMAN, C.R. 1961. The contribution of the alder trees (Alnus tenuifolia) to the primary productivity of Castle Lake, California. Eco$\log y, 42: 282-288$.

GRANHALL, U. \& LUNDGREN, A. 1971. Nitro- gen fixation in Lake Erken. Limnnol. Oceaniogr. 16: 711-719.

HASLAM, S.M. 1978. River Plants. Cambridge Univ. Press. Cambridge. 396 págs.

MERINO, E. \& BERMUDEZ DE CASTRO, F. 1982. Estudios en ecosistemas diazotróficos. I. Alisedas de la cuenca del río Alberche. Bol. Est. Cent. Ecol., en prensa.

SCHMITZ, M.F. \& BERMUDEZ DE CASTRO, F. 1982. Estudios en ecosistemas diazotróficos. II. Alisedas del noroeste de Guadalajara. Bol. Est. Cent. Ecol., en prensa.

SILVESTER, W.B. 1977. Dinitrogen fixation by plant associations excluding legumes. In: $A$ Treatise on Dinitrogen Fixation. N. Agronomy and Ecology. R.W.F. HARDY y A.H. GIBSON (eds.) John Wiley and Sons. New York. págs: $141-190$.

STANDARD METHODS FOR THE EXAMINATION OF WATER AND WASTEWATER. 1980. APHAAWWA-WPCF. Anier. Pub. Health Ass. Washington. 1.134 pägs. 